\title{
COG-C9710 APL Regimen
}

National Cancer Institute

\section{Source}

National Cancer Institute. COG-C9710 APL Regimen. NCI Thesaurus. Code C67480.

A regimen consisting of an induction phase with tretinoin (ATRA), cytarabine and idarubucin followed by a consolidation course of tretinoin and daunorubicin, used for the treatment of acute promyelocytic leukemia (APL). A prolonged maintenance regimen including tretinoin and methotrexate, with or without mercatopurine (6-MP), is also part of the treatment plan. 